\title{
From conceptual modeling to a map
}

\author{
Dariusz Gotlib, ${ }^{\mathrm{a}}$ Robert Olszewski ${ }^{\mathrm{a}}$ \\ ${ }^{a}$ Warsaw University of Technology, Department of Cartography, Warsaw, Poland; \\ r.olszewski@gik.pw.edu.pl,dariusz.gotlib@gmail.com
}

\begin{abstract}
Nowadays almost every map is a component of the information system. Design and production of maps requires the use of specific rules for modeling information systems: conceptual, application and data modelling. While analyzing various stages of cartographic modeling the authors ask the question: at what stage of this process a map occurs. Can we say that the "life of the map" begins even before someone define its form of presentation? This question is particularly important at the time of exponentially increasing number of new geoinformation products. During the analysis of the theory of cartography and relations of the discipline to other fields of knowledge it has been attempted to define a few properties of cartographic modeling which distinguish the process from other methods of spatial modeling. Assuming that the map is a model of reality (created in the process of cartographic modeling supported by domainmodeling) the article proposes an analogy of the process of cartographic modeling to the scheme of conceptual modeling presented in ISO 19101 standard.
\end{abstract}

Keywords: cartographic modeling, map definition, geographic information science, conceptual schema, cartographic formal-ism

\section{Introduction}

The modeling process plays an important role in many fields of study, cartography and geographic information science included. The essence of the modeling process and models as such - is a generalized representation of objects or phenomena. A model makes it possible to extract certain features of the phenomenon, ones that are interesting from a given point of view. There are different theories and concepts regarding the possibility and intentionality of the process of modeling reality. Empiricists like van Fraassen (1980) only allow for observables to qualify as such, while realists like Bogen and Woodward (1988) do not impose any such restrictions.

A map is one of many possible models of reality. It is a model with specific features that can be found when analyzing the theory and practice of cartography. This model's main goal is to show mutual relations between objects, phenomena and processes in space in a way that would enable the user (the recipient) to localize objects, to analyze the temporal and spatial variability of selected phenomena effectively, and to explore the space.

The overwhelming majority of contemporary maps is done by means of the digital process, usually using GIS technology, and is stored in a spatial database. Therefore, their design and construction should follow the same rules that apply to the development of databases and information systems. Conceptual modeling is the starting point of creating a map; as a result, a conceptual schema is formed. The next step of this process is preparing data that follow the schema, leading to the development of a map.

However, the process of creating a map is not always viewed exactly as it has been described above. It is sometimes viewed as a process completely independent of the standard modeling process detailed in, e.g. ISO 19100 norms. Until relatively recently, it has been quite commonly believed that cartographic modeling is limited to ways of constructing geovisualization (Kraak, Ormeling, 1996). Conceptual modeling that leads to developing a spatial database schema did not use to be or, sometimes, is still not - connected with the cartographic process. The last twenty years, however, have been a period of extraordinary development in communications technology. The au-thors of this article believe that the idea of cartographic modeling as solely the process of constructing geovisualization is an outdated and unjustified view.

Developing any kind of map, including those done in the past without digital technologies, required conducting modeling. As a result of which, the map's subject matter was decided, the ways of showing connections between objects were defined, the attributes of the objects to be seen by the recipient were determined, the generalizations were designed, and so forth. Cartographers, often in cooperation with specialists from various fields of study, per-formed this task; the specialists were selected depending on the subject matter that was supposed to be represented by the map. How was that process different from the contemporary process defined in ISO norms as "geographic information modeling"? The authors of this article believe that the only difference is that now this process is formalized, whereas developing classic maps in the era before spatial database technologies had the characteristics of in-formal and extremely diverse processes.

Throughout the centuries, a map as a model of reality was communicated graphically - the recipient was given classic, analogue, hand-painted, engraved or printed maps. For a long time, it was the only effective way of transferring information about the space. Along with the 
emergence and development of geoinformation systems, there are significantly more possibilities when it comes to transferring information. It should be noted that, analogically, the needs of users of the spatial information have increased as well. Also, the audience is now wider, as it is no longer restricted to human beings: unmanned airborne vehicles, engineering robots or autonomous cars need such pieces of information too. What it means is that a cartographic model should be developed in a way that enables its effective usage in systems that do not use graphical forms of communication. The classic graphical form, ubiquitous throughout the centuries, is becoming just one of multiple forms of communicating cartographic information. Therefore, this form does not define the contemporary concept of a map or the essence of cartographic modeling. Geovisualization is just one of multiple ways of communicating cartographic information.

\section{The essence of a map and cartographic modeling}

Because of the development of technological possibilities and the accompanying growing needs of the modern geoinformation society, the "classic", restrictive definition of a map, that is a graphical expression of a part of space on Earth mapped on a surface, is just history. A map has identity and it exists regardless of its form of com-munication. To realize this, a simple question will do: if a user of a navigation system turns off the screen of the mobile device, does the map cease to exist? It is a rhetorical question as the answer is obvious: no, it does not. Ac-cording to the modern understanding, a map is not a graphic image, but an appropriately defined special structure of information (Gotlib 2011, Baranowski et al. 2016). A precisely defined process of cartographic modeling leads to creating a map. In this context, cartographic modeling should be understood in a broader sense, both as a process of creating a conceptual model of space (enabling its analysis and understanding) and as a process of modeling the way of cartographic presentation (facilitating its visualization).

As the authors of "Models in Science" (Stanford Encyclopedia of Philosophy) point out: models can perform two fundamentally different representational functions. On the one hand, a model can be a representation of a selected part of the world (the "target system"). Depending on the nature of the target, such models are either models of phenomena or models of data. On the other hand, a model can represent a theory in the sense that it interprets the laws and axioms of that theory. These two notions are not mutually exclusive as scientific models can be representations in both senses at the same time.

Thus, a properly developed cartographic model not only enables the symbolization of a fragment of space, emphasizing the features of particular objects and their mutual relations, but is also a tool used to analyze and under-stand the space itself. Just as analyzing a representative sample of a population in the contemporary statistical science, inferences regarding the characteristics of the entire population, not the sample alone, are made - when analyzing a cartographic model we indirectly get to know the space, not the model alone (Olszewski, 2015).

Such a broad definition of a map and the process of cartographic modeling require raising a question about the essence of information modeling and how it is connected with cartography (seen as a discipline devoted to modeling and communicating a certain type of information, that is spatial information).

In this context, it seems appropriate to make a reference to descriptions of the process of conceptual modeling widely used in the geographical information science. The way conceptual schemas are created has been described in ISO 19101 norm (Fig. 1). They are developed in the process of conceptual modeling, using appropriate conceptual formalisms. A conceptual schema can be depicted by means of various notations; UML graphical notation is currently the most common. Subsequently, a specific database is formed on the basis of the conceptual schema. The authors believe that cartographic modeling should be treated as a subset of the process of conceptual modeling defined in ISO 19101.

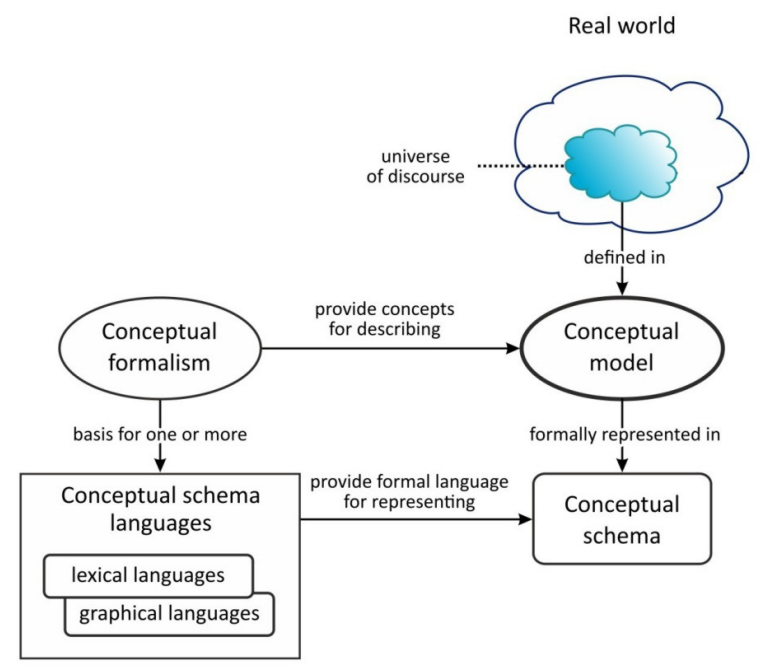

Fig. 1. From the real world to the conceptual schema (based on ISO 19101 norm).

During the process of cartographic modeling the objects, attributes and relations between the objects, which are important from the map users' point of view, are being selected from the surrounding reality. It is a process that is also typical for all conceptual modeling processes. However, the authors believe that to call such a process "carto-graphic", certain conditions must be met.

When analyzing the theory of cartography and its connections with other fields of knowledge, attempts have been made to define the properties of cartographic modeling that distinguish the process from other methods of spatial modeling (Baranowski, Gotlib, Olszewski 2017). The properties defined in the aforementioned paper are the following:

1)portrayal of space,

2)identification of types of objects and phenomena, 
3)description of spatial relationships between objects,

4)localization in an applied reference system,

5)deliberate choice of a certain level of generalization compliant to the map's objective,

6)symbolization based on knowledge,

7)aware authorship of the message,

8)explicitness of communication (conformity between intention and reception).

Cartographic modeling and the usage of appropriate conceptual formalisms (e.g. UML) should result in a map scheme. A map scheme enables organizing specific spatial data in a systematic collection of data with a defined structure. If cartographic modeling (with the properties mentioned above) was done at an earlier stage, this process will directly lead to creating a specific map for a given area. The map (as a specific collection of data describing specific objects of the real world and the relations between them) can be recorded in the database. It is its appropriate structure, not the form of communication, which makes its identity. Nowadays there are many forms of communicating information (printed graphics, holography, sound, touch, text, binary signal, and so on). The form of communicating a spatial model, namely the process of defining a cartographic presentation, can and should be subject to formalization (Gotlib 2011, Gotlib 2012).

As it has been mentioned, in the process of conceptual modeling (Fig. 1), appropriate conceptual formalisms are applied, so that the conceptual schema is recorded in an unambiguous way. Analogically, in the process of developing a map, formalisms and languages of cartographic symbolization are used. Their goal is to determine the way the spatial properties of the real world objects are represented in the database, as well as to make sure the information about the space is unambiguously communicated to the recipient. In the process of defining the information transfer, the language of graphic symbols is the formalism that is most extensively discussed in the theory of cartography and most commonly used in practice. But the spatial information transfer can also be done by means of a textual description (e.g. a description of the route in the navigation system), a sonic description (a description of a space in an audio tourist guide), or by means of a binary notation that allows an autonomous control of the air-craft's, ship's or - soon - autonomous vehicle's autopilot (Gotlib 2012). The authors believe, the form in which the model's map is presented is of secondary importance. For historical reasons, throughout the centuries the graphical representation was the dominant tendency in this process. At the moment, deep reflection on an non-graphical form of a cartographic model representation is necessary to enable effective M2M (machine-to-machine) communication that uses spatial data and because of the growing needs of the modern geoinformation society.

Apart from the graphical language, the remaining forms of communication are currently not fully defined or extensively discussed in the theory of cartography. This area requires a number of studies and remains an incredibly interesting field of inquiry, both from a scientific and a practical perspective. The aforementioned solutions are illustrated with a scheme that is an expanded version of the ISO 19101 scheme (Fig. 2).

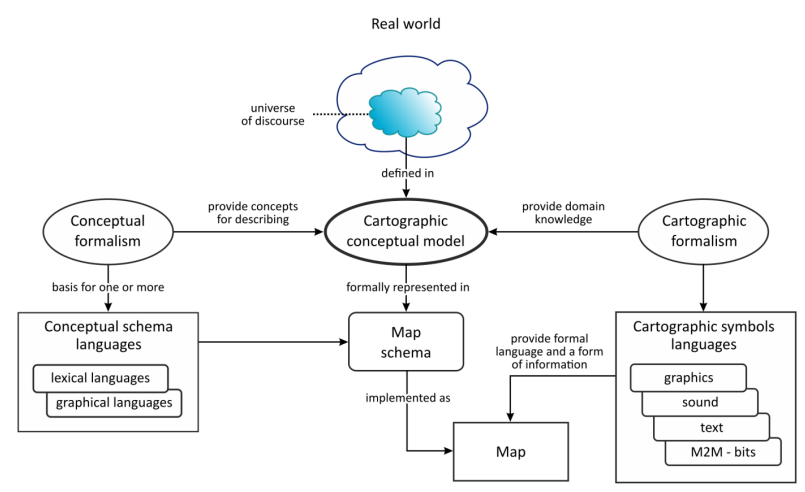

Fig. 2. From the real world to a map (the authors' own work)

According to this approach, developing a cartographic conceptual modeling requires using conceptual formalisms as well as cartographic formalisms. The first group enables a proper definition of a map's conceptual schema; the second, a proper definition of a cartographic presentation. Still, in the process of creating a cartographic conceptual model cartographic formalisms should be taken into account. These processes are connected with each other. First, an appropriate data model must be designed to ensure a proper cartographic communication.

It should be noted, that cartographic formalisms should not be solely associated with graphical methods of communicating information. A map, in a broader sense, can be communicated to the recipient by means of cartographically correct sonic/descriptive transfer. In the age of the IoT (Internet of Things), it is equally important to communicate formalized binary cartographic information between machines (M2M), facilitating location, navigation, etc., without any human intervention.

When discussing cartographic modeling, the issue of domain modeling (branch modeling) should also be noted. The authors believe that the cartographic modeling focuses on the correct storage and transference of information regarding the location of objects and phenomena in space and their spatial relations that are interesting from the point of view of the recipient to the recipient. These objects, phenomena and processes are defined and described in accordance to the theory and practice of various fields of study. Understanding these phenomena or isolating specific objects (abstraction) is sometimes beyond the classic cartographic knowledge. Often, a cartographer uses only results of domain modeling or assists in modeling processes conducted by other scientists and practitioners. Creating a weather forecast map requires the work of meteorologists and the usage of weather models; developing a geological map requires geological knowledge or historical when creating historical maps. What it means is that creating an wellmade map (especially a thematic map) requires not only strictly cartographical skills, but also specialist 
knowledge of a domain, unrelated to the cartographic methodology. A simplified illustration has been provided in Figure 3.

An well-made map is created only as a result of the consistent application of rules regarding cartographic modeling. A specialist in history can also develop an high-quality map. To do so, he/she must have an appropriate carto-graphic knowledge, as the process of developing a historical map is not a process of historical modeling, but of cartographic modeling. To perform cartographic modeling, historical analysis and historical modeling of an event or of a course of events has to be done in advance. It should also be noted that not every historical model has to be rep-resented by means of a map, so there will not always be used cartographic modeling.

The process of creating weather forecast maps can be described in a similar way. Experts in this domain develop weather models. Processing the permanently gathered meteorological data is also done (usually digitally) without a cartographer. However, if a meteorologist wants to create a weather map, he/she has to follow the cartographic methodology and conduct cartographic modeling. Thus, the process of cartographic modeling facilitates an effective - methodologically accurate as well as informative for the recipient - spatial information communication, by means of various kind of maps. The cartographic methodology makes it possible to develop both simple geovisualization as well to present phenomena that are highly dynamic, e.g. spatial distribution of temperature, wind power, etc.

Thus, implementing accurate cartographic preparations requires combined forces of various specialists, usually as soon as at the stage of conceptual modeling. Therefore, a conceptual schema of a map must take into account cartographic requirements and keep properly stored and recorded domain knowledge.

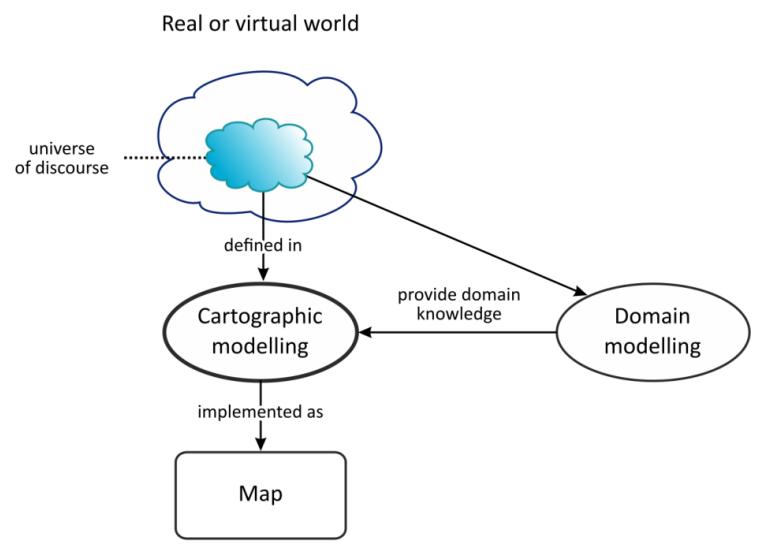

Fig. 3. The role of domain modeling in the map development process (the authors' own work)

\section{Conclusions}

Despite the development of geoinformation systems and the emergence of a vast number of various products communicating spatial information, there are still many people (especially outside cartography) who associate maps only with geovisualization. Therefore, the authors believe that it is necessary to consistently change such a way of thinking, as it may not only detrimentally affect the development of cartography as such, but also restrict the development of geoinformation society. In fact, this development is contingent upon a skillful utilization of ac-curate cartographic models of space - when it comes to human-human, human-machine as well as, more and more often, machine-machine communication.

Developing every map, including an analogue one, required and still requires conducting the process of conceptual modeling. In the past this process did not use to be formalized. An analysis of conceptual modeling processes and an attempt to identify cartographic modeling as one of specific cases of this modeling, both lead to the aware-ness that there is no logical justification for perceiving a map only in connection with a form of graphically communicating information to the recipient. A map means arranging data and giving them a proper structure in a way, that is appropriate for cartography, according to a certain data model to ensure the optimum spatial information communication.

To sum up, it could be said that the definition of a map comprises the structure of information storage (obligatory) and a defined form of presentation (optional). Cartographic modeling should be treated as the overall process, based on conceptual modeling, which leads to the creation of a map. The process of cartographic modeling not only (not even predominantly) allows the symbolization of the space, but also its exploration and understanding by means of a model. Thus, cartographic models enable posing fundamental questions of a principal nature: in semantics (what is the representational function that models perform?), ontology (what kind of things are models?), epistemology (how do we learn with models?), and in philosophy of science (how do models relate to the theory)? Answering these questions is the objective of the authors' further research.

\section{References}

Baranowski M., Gotlib D., Olszewski R. (2016), Properties of cartographic modelling under contemporary definitions of a map, in: Polish Cartographical Review, Polskie Towarzystwo Geograficzne, vol. 48, nr 3, pp. 91-100.

Baranowski M., Gotlib D., Olszewski R. (2017), In Search of the Essence of Cartography (this conference).

Bogen, J., Woodward, J. (1988), "Saving the Phenomena," Philosophical Review 97: 303-352.

Gotlib D. (2011), Metodyka prezentacji kartograficznych w mobilnych systemach lokalizacyjnych i nawigacyjnych, Prace Naukowe PW, seria Geodezja, vol. 48, Oficyna Wydawnicza PW

Gotlib D. (2012), Mobile maps - modelling of cartographical presentation, Geoinformatica Polonica, no. 11 , pp. 57-65

ISO 19101 Geographic information - Reference model 
Kraak, M.-J. Ormeling F. J. (1996). Cartography, the Visualization of Spatial Data. London, Addison Wesley Longman.

Olszewski, R. (2015), Artifical Intelligence algorithms in Geographic Information Systems, in: AI: LAW, PHILOSOPHY \& GEOINFORMATICS Jankowska M., Pawełczyk M., Kulawiak M. (ed.), Wydawnictwo Polskiej Fundacji Prawa Konkurencji i Regulacji Sektorowej Ius Publicum, ISBN 978-83-64611-88-9, pp. $29-40$

Stanford Encyclopedia of Philosophy, Summer 2009 Edition, https://plato.stanford.edu/archives/sum2009/

van Fraassen, Bas C. (1980), The Scientific Image. Oxford: Oxford University Press. 